\title{
From control to elimination: a spatial-temporal analysis of malaria along the China-Myanmar border
}

\author{
Fang Huang ${ }^{1}$, Li Zhang ${ }^{1}$, Jing-Bo Xue ${ }^{1}$, Hong-Ning Zhou², Aung Thi ${ }^{3}$, Jun Zhang ${ }^{4}$, Shui-Sen Zhou',
} Zhi-Gui Xia ${ }^{1 *}$ and Xiao-Nong Zhou ${ }^{1 *}$

\begin{abstract}
Background: Malaria cases have declined significantly along the China-Myanmar border in the past 10 years and this region is going through a process from control to elimination. The aim of this study is to investigate the epidemiology of malaria along the border, will identify challenges in the progress from control to elimination.

Methods: National reported malaria cases from China and Myanmar, along with the data of 18 Chinese border counties and 23 townships in Myanmar were obtained from a web-based diseases information reporting system in China and the national malaria control program of Myanmar, respectively. Epidemiological data was analyzed, including the number of reported cases, annual parasite index and proportion of vivax infection. Spatial mapping of the annual parasite index (API) at county or township level in 2014 and 2018 was performed by ArcGIS. The relationship of malaria endemicity on both sides of the border was evaluated by regression analysis.

Results: The number of reported malaria cases and API declined in the border counties or townships. In 2014, 392 malaria cases were reported from 18 Chinese border counties, including 8.4\% indigenous cases and $91.6 \%$ imported cases, while the highest API (0.11) was occurred in Yingjiang County. There have been no indigenous cases reported since 2017, but 164 imported cases were reported in 2018 and 97.6\% were imported from Myanmar. The average API in 2014 in 23 Myanmar townships was significantly greater than that of 18 Chinese counties $(P<0.01)$. However, the API decreased significantly in Myanmar side from 2014 to $2018(P<0.01)$. The number of townships with an API between 0 and 1 increased to 15 in 2018, compared to only five in 2014, while still four townships had API >10. Plasmodium vivax was the predominant species along the border. The number of reported malaria cases and the proportion of vivax infection in the 18 Chinese counties were strongly correlated with those of the 23 Myanmar townships $(P<0.05)$.
\end{abstract}

Conclusions: Malaria elimination is approaching along the China-Myanmar border. However, in order to achieve the malaria elimination in this region and prevent the re-establishment of malaria in China after elimination, continued political, financial and scientific commitment is required.

\footnotetext{
*Correspondence: xiazg@nipd.chinacdc.cn; zhouxn1@chinacdc.cn

${ }^{1}$ National Institute of Parasitic Diseases, Chinese Center for Disease Control and Prevention, Chinese Center for Tropical Diseases Research, WHO Collaborating Center for Tropical Diseases, National Centre for International Research on Tropical Diseases, Ministry of Science and Technology, Key Laboratory of Parasite and Vector Biology, Ministry of Health, Shanghai 200025, China

Full list of author information is available at the end of the article
} permits use, sharing, adaptation, distribution and reproduction in any medium or format, as long as you give appropriate credit to the original author(s) and the source, provide a link to the Creative Commons licence, and indicate if changes were made. The images or other third party material in this article are included in the article's Creative Commons licence, unless indicated otherwise in a credit line to the material. If material is not included in the article's Creative Commons licence and your intended use is not permitted by statutory regulation or exceeds the permitted use, you will need to obtain permission directly from the copyright holder. To view a copy of this licence, visit http://creativecommons.org/licenses/by/4.0/. The Creative Commons Public Domain Dedication waiver (http://creativeco mmons.org/publicdomain/zero/1.0/) applies to the data made available in this article, unless otherwise stated in a credit line to the data. 
Keywords: Malaria, Control, Elimination, China-Myanmar border

\section{Background}

Malaria is a life-threatening disease caused by Plasmodium parasites that are transmitted to human through the bites of infected female Anopheles mosquitoes. It remains one of the most common infectious diseases in the world, with the number of confirmed cases estimated at 228 million with 405000 deaths in 2018, compared with 416000 estimated deaths in 2017 and 585000 in 2010 [1]. The emergence and spread of artemisinin resistant Plasmodium falciparum has become one of the greatest challenges to malaria control and elimination in the Greater Mekong Subregion (GMS) [2-5]. Recent efforts to fight malaria in the GMS have yielded impressive results. According to the latest World Health Organization (WHO) estimates, the reported number of malaria cases fell by 76\% between 2010 and 2018, and malaria deaths fell by $95 \%$ over the same period [1]. Driven by the artemisinin resistance, WHO has implemented a strategy to eliminate $P$. falciparum from six countries in the GMS by 2025, in response to the threat of an untreatable multi-drug resistant parasite [6]. Representatives from six countries signed the "Ministerial Call for Action to
Eliminate Malaria in the Greater Mekong Subregion by $2030 "$ in 2018 [7].

Historically, malaria was one of the most serious infectious diseases in China [8]. During the past six decades, China has made great contributions towards malaria control [8]. In 2010, the Chinese government launched the National Malaria Elimination Programme (NMEP) $2010-2020$ with the goal of eliminating malaria by 2020 , sustaining a malaria-free status and prevent re-establishment beyond 2020 (Fig. 1) [9, 10]. Over the following 5 years, malaria cases decreased substantially. In 2017, no indigenous malaria cases were reported for the first time [11]. In 2020, China is close to malaria elimination nationwide. However, Yunnan Province in southern China, which borders Myanmar, Vietnam and Laos, remains the key focus of the NMEP.

Myanmar has the highest malaria burden and is a major source of malaria exportation in the GMS [12, 13]. In the past decade, Myanmar has made significant progress in reducing malaria morbidity and mortality with the financial support for major improvements in access to early diagnosis and appropriate treatment. Malaria morbidity

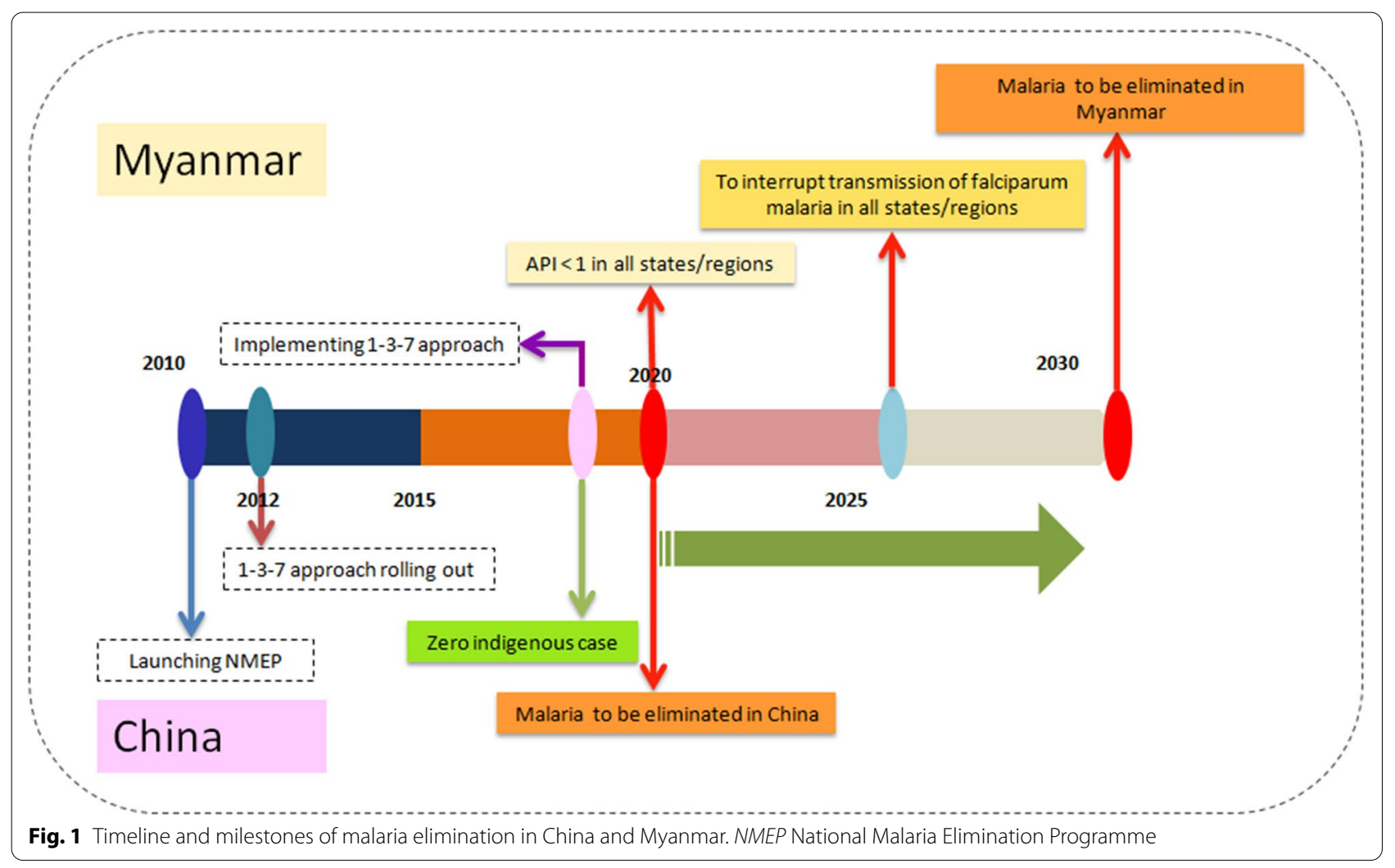


was reduced by $72 \%$ in 2016 compared with 2012 and there was a $95 \%$ reduction in malaria deaths within the same period [14]. However, Myanmar was still reported to account for the majority of malaria cases and deaths in the GMS $[7,15,16]$. Meanwhile, conflict-affected settings and regions with high population mobility have enhanced the programmatic challenges of moving towards elimination [17-19]. Following the recommendation by the WHO Malaria Policy Advisory Group to eliminate $P$. falciparum malaria in the GMS by 2030 in 2014, which was technically, operationally and financially feasible, in 2016 the National Malaria Control Programme (NMCP) in Myanmar set the goal of eliminating P. falciparum malaria by 2025 and eliminating malaria in all states and regions by 2030 (Fig. 1) [20].

A total of 18 counties in Yunnan Province, China and 23 townships in Myanmar share the border of $1997 \mathrm{~km}$. The border areas on both sides are outlying, hard to reach and poverty-stricken inhabited by the minority nationalities [21]. Currently, there are 13 national and provincial frontier ports, 427 passageways and countless shortcuts along the border. The climate, landscape and vectors of malaria transmission on both sides of the border are similar. In the last 10 years, malaria incidence has declined remarkably and the progress was made possible through greater access to effective malaria control tools, particularly artemisinin-based combination therapies (ACTs) for malaria treatment, rapid diagnostic tests (RDTs), and insecticide-treated nets (ITNs). Therefore, we undertook a spatial and temporal analysis to investigate the changing pattern of malaria along this border and identify the key priorities and challenges in the progress from malaria control to elimination.

\section{Methods \\ Study site}

The study areas include 18 counties in Yunnan Province, China and 23 townships in Kachin, North Shan and East Shan states of Myanmar (Fig. 2).

Yunnan Province, located in the southern China, spans approximately $394000 \mathrm{~km}^{2}$ with a population of 48.3 million. Yunnan has high mountains bordering Tibet and Sichuan in the west, a hilly plateau in the east bordering Guangxi and Guizhou provinces/autonomous regions, and a tropical zone in the south sharing the border with Vietnam, Laos, and Myanmar. The average daily high temperature is around $24^{\circ}$ centigrade and the climate is almost moderate, but also offers a

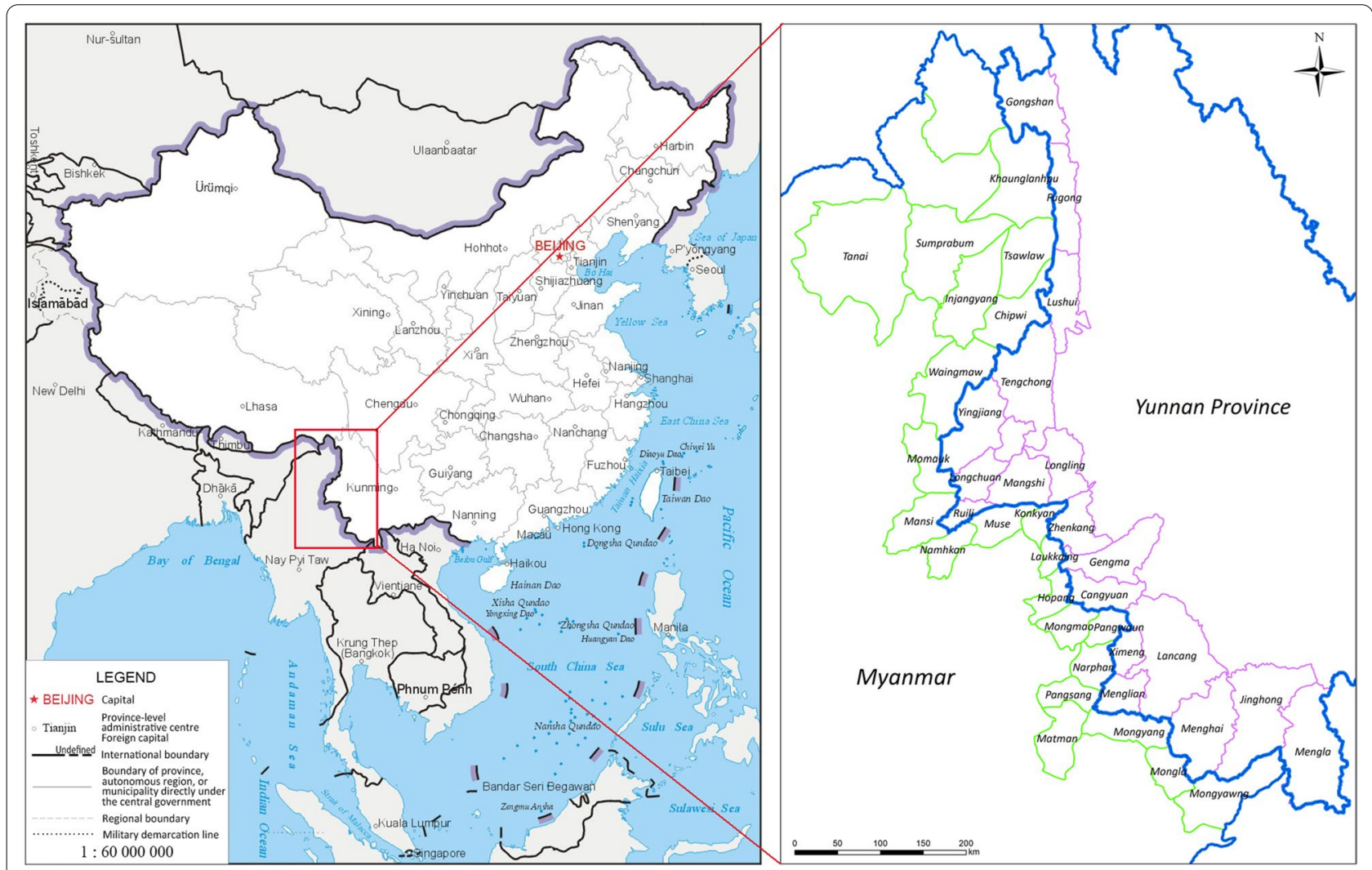

Fig. 2 Map of the borders between the China and Myanmar. The China map is from National Geomatics Center of China with the link https://www. ngcc.cn/ngcc/. And the map is correct by checking with that from the web link: https://bzdt.ch.mnr.gov.cn/ 
few sultry months with high humidity and high temperatures. In the western Yunnan, it has distinct dry and rainy seasons. A total of 18 counties lie along the border with Myanmar.

Kachin State, also called Jinghpaw Mung is the northernmost state of Myanmar. It is bordered by Tibet and Yunnan in China in the north and east, respectively. The average temperature in Kachin state is $25^{\circ}$ centigrade and the average precipitation of rainfall is around $2100 \mathrm{~mm}$ per year. The rains are very abundant from June to August. Kachin State covers four districts, Myitkyina, Bamaw, Moehnyin, and Putao and 18 townships. The population is approximately 1.6 million. Ten townships in Kachin share borders with China. Shan State, located in the northeast of Myanmar, is traditionally divided into three sub-states: North Shan, East Shan, and South Shan states. Shan State covers $155800 \mathrm{~km}^{2}$, almost a quarter of the total area of Myanmar. Most of Shan State is a hilly plateau, which together with the higher mountains in the north and south forms Shan Hills system. Eleven townships in North Shan state, and two from East Shan State border China to the north. The total population is around 5.8 million.

\section{Case data collection}

Malaria data from China were collected from the Chinese Infectious Disease Report System (CIDRS), a web-based reporting system for individual case and data management for notifiable infectious diseases from 2005 to 2018. The classification of malaria cases in China was made according to the criteria from the national guidelines, and included epidemiologically indigenous and imported cases as well as laboratoryconfirmed cases defined as cases confirmed using any of the diagnostic tests, such as polymerase chain reaction (PCR), rapid diagnosis test (RDT), and microscopy examination and clinically diagnosed cases defined as patients with malaria-like symptoms without detection of parasites through blood examination [22]. The malaria case data from 18 border counties was extracted accordingly for mapping the malaria distribution at the county level.

Malaria data from Myanmar was obtained from the NMCP. The cases included probable malaria cases and confirmed cases, defined as positive by diagnostic testing including microscope examination and/or RDTs. The malaria cases and related epidemiological data from 23 border townships were collected by NMCP along with another five non-government organizations: Human Poverty Action, Myanmar Council of Churches, Myanmar Medical Association, Medical Action Myanmar, and Population Service International.

\section{Data analysis}

Data analysis was processed using Microsoft Excel 2017 and SAS software (SAS Institute Inc, Version 9.2, Cary, NC, USA). Annual parasite index (API) is the definition of the number of confirmed new cases from malaria registered in a specific year, expressed per 1000 individuals under surveillance, for a given country, territory, or geographic area. API = total confirmed cases in a year $\times 1000 /$ total population. The APIs were transformed to logarithms with a base of 2.5 to attain a normal distribution and homogeneity of variance. APIs of 23 Myanmar townships and 18 Chinese counties in 2014 and APIs of the former and imported malaria cases of the latter in 2018 were mapped by using ArcGIS 10.1 (Environmental Systems Research Institute, Inc, Redlands, CA, USA) to identify the geographical distribution of malaria on both sides. The relationship between the number of reported malaria cases and APIs on both side of the border was analyzed by a linear regression mode. A $P$ value $<0.05$ was used to evaluate differences with statistical significance.

\section{Results}

Malaria endemicity in China and Myanmar at country level Reported malaria cases from China, Myanmar and the border areas were collected to assess the trend of the malaria transmission from 2005 to 2018 . The reported cases decreased to a low level with only thousands of cases in 2015-2018 in China compared with the hundreds of thousands of cases before 2010 when NMEP had not been launched. A total of 42319 malaria cases were reported in the entire country in 2005 and this declined to 2678 cases in 2018 (Fig. 3a). The number of counties with indigenous malaria cases decreased from 1168 in 2005 to one in 2016 and zero in 2017. The proportion of imported cases was $18.3 \%$ in 2005 and then increased and was maintained at more than $90 \%$ since 2012 and up to almost 100.0\% except for a few induced cases from 2017 (Fig. 3a). In 2017, no indigenous cases were reported in the whole country for the first time.

A total of 76518 malaria cases were reported in Myanmar in 2018 compared with 516041 in 2005, representing a decline of $85.2 \%$ (Fig. $3 \mathrm{~b}$ ). The trend of malaria reported cases presented a single peak pattern. The number of cases steadily ascended from 2005 to 2010 but descended remarkably from 2010 to 2018 . The proportion of confirmed malaria cases was only $11.5 \%$ (59 $405 / 516041)$ and $11.7 \%$ (62 813/538 110) in 2005 and 2006, respectively, but has significantly increased since 2007 and reaching to $97.9 \%$ (465 294/475 509) in 2011 (Fig. 3b). All the reported malaria cases have been confirmed since 2012. 


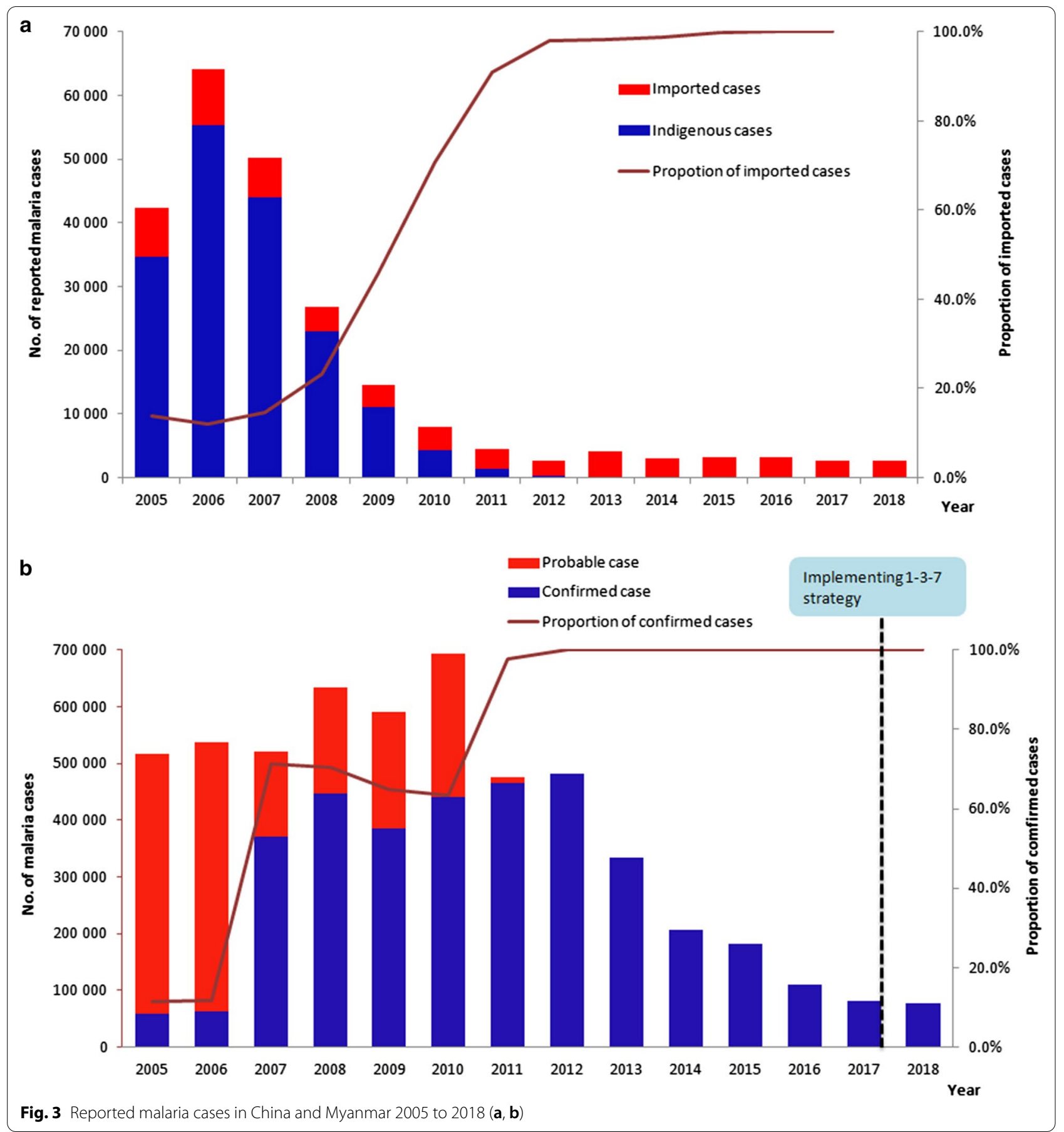

Reported malaria cases and API at county or township level Both the number of reported malaria cases and API declined in the border counties or townships on both sides. In 2014, 392 malaria cases were reported from 18 counties in Yunnan Province of China, which included $33(8.4 \%)$ indigenous cases and 359 (91.6\%) imported cases. Ten counties reported no indigenous malaria cases and seven counties (accounting for 38.9\%, 7/18) displayed an API range of $0-0.1$. The highest API (0.11) was occurring in Yingjiang County (Fig. 4a), which was also the last indigenous malaria case as reported in the whole country. Since 2017, no indigenous cases have been reported in China, including these border counties. In 2017, a total of 263 imported malaria cases reported 

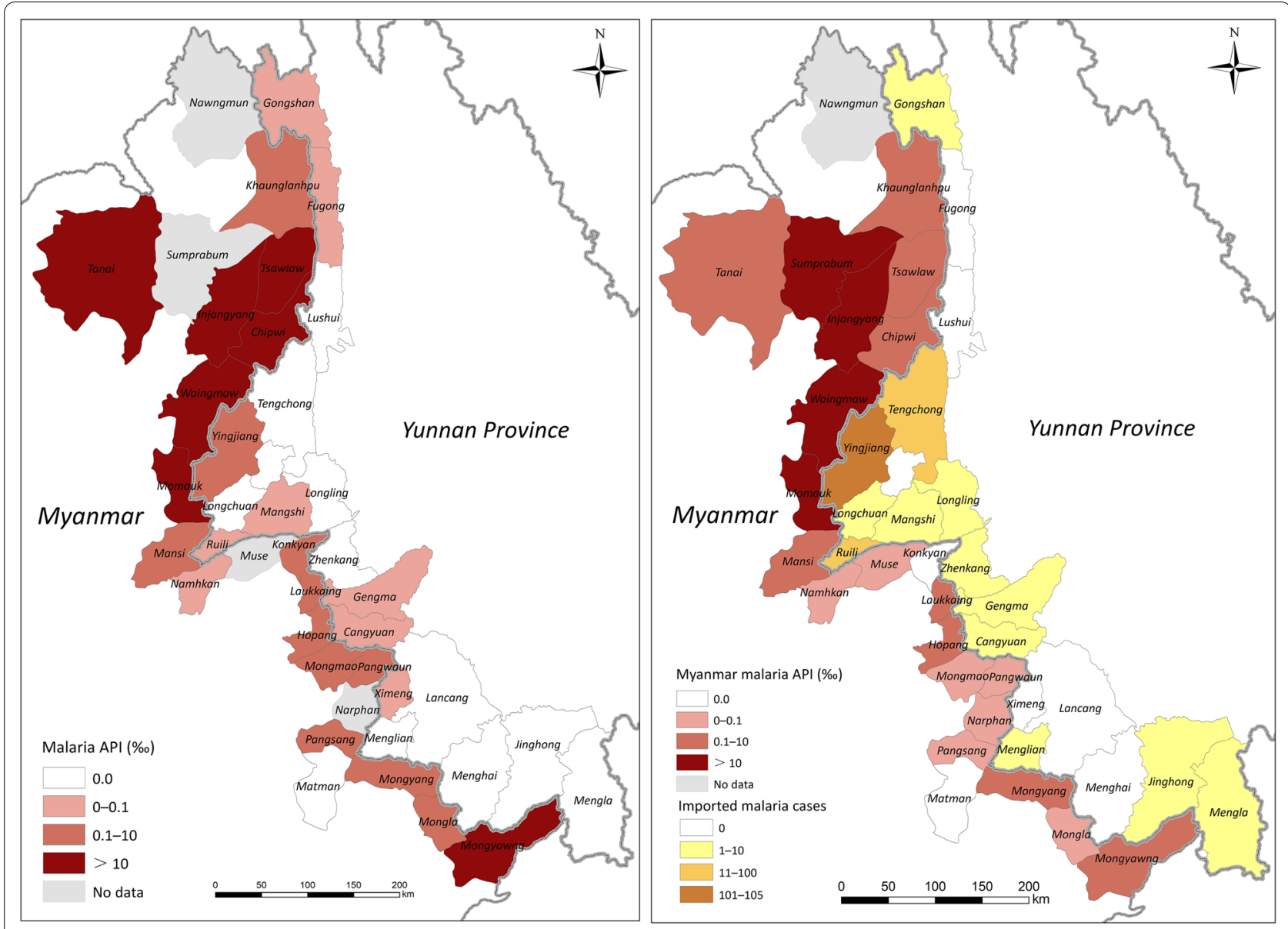

Fig. 4 API mapping based on county or township level in 2014 and 2018

in 18 border counties and $97.0 \%(255 / 263)$ were from Myanmar. The distribution of imported malaria cases in 2018 was mapped (Fig. 4b). There were 164 imported cases reported in 2018 and 97.6\% (160/164) were imported from Myanmar (Table 1): 64.0\% (105/164) were reported in Yingiiang County, followed by Tengchong $(11.0 \%, 18 / 164)$ and Ruili $(7.3 \%, 12 / 164)$. In addition, the percentage of $P$. falciparum imported from Myanmar was decline steadily from 2014 to 2018 while the percentage of $P$. vivax imported from Myanmar was no significantly different in the same period (Table 2).

The average API in 2014 in 23 townships in Myanmar was significantly greater than that of the 18 counties in China $(P<0.01)$. In 2014 , only one township Matman in

Table 1 The infection place of malaria reported cases in 18 Chinese border counties from 2014 to 2018

\begin{tabular}{|c|c|c|c|c|c|c|}
\hline \multirow[t]{2}{*}{ Year } & \multicolumn{4}{|c|}{ Imported cases, $n$ (\%) } & \multirow[t]{2}{*}{ Indigenous case, $n(\%)$} & \multirow[t]{2}{*}{ Total, $n$} \\
\hline & Myanmar & Other counties in GMS & Africa & Others & & \\
\hline 2014 & $351(89.5)$ & $8(2.0)$ & $0(0.0)$ & $0(0.0)$ & $33(8.4)$ & 392 \\
\hline 2015 & $447(93.5)$ & $19(4.0)$ & $0(0.0)$ & $1(0.2)$ & $11(2.3)$ & 478 \\
\hline 2016 & $299(95.8)$ & $7(2.2)$ & $5(1.6)$ & $0(0.0)$ & $1(0.3)$ & 312 \\
\hline 2017 & $255(97.0)$ & $6(2.3)$ & $1(0.4)$ & $1(0.4)$ & $0(0.0)^{\mathrm{a}}$ & 263 \\
\hline 2018 & $160(97.6)$ & $0(0.0)$ & $4(2.4)$ & $0(0.0)$ & $0(0.0)^{\mathrm{a}}$ & 164 \\
\hline
\end{tabular}

GMS Greater Mekong Subregion

a There was no indigenous malaria cases reported in 2017 and 2018 


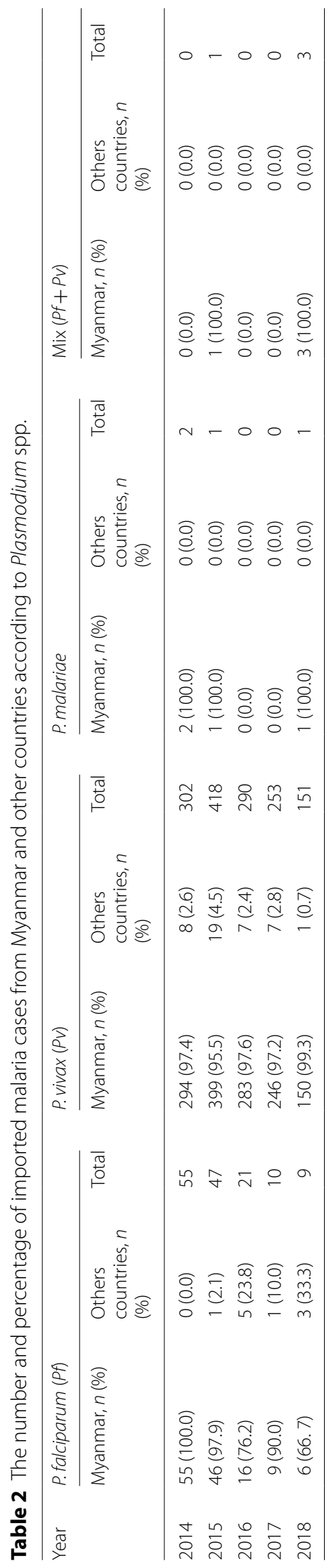


North Shan State, no malaria cases reported. There were five and six townships with API of $0-1$ and $1-10$, respectively. Seven townships showed API of more than 10 and six out of them were located in Kachin State (Fig. 4). The highest API was 55.2 reported from Injangyang township. In 2018, Matman and Konkyan reported no malaria cases. The API decreased significantly in these 23 townships in Myanmar from 2014 to $2018(P<0.01)$. The number of townships with APIs between $0-1$ increased to 15 in 2018, compared to only five in 2014 (Fig. 4). However, there were still four townships with APIs of 10-50 and two townships with APIs of 1-10. The highest API was 19.6, in Sumprabum township in northern Kachin State.

\section{Proportion of $P$. vivax}

P. vivax was the predominant malaria parasite along the China-Myanmar border. In 2014-2018, the average proportion of $P$. vivax infection in the 18 Chinese counties and the 23 Myanmar townships was $91.1 \%$ (range: 84.3-96.3\%) and 61.2\% (range: 37.9-86.8\%), respectively (Fig. 5). P. vivax infection was more common in China than in Myanmar. The proportion of $P$. vivax cases in North Shan was highest (66.5\%), followed by
Kachin State and East Shan State. The trend of the proportion of $P$. vivax cases showed a slight increase in the 18 border counties in China, while ascending more on Myanmar side. Interestingly, the proportion of vivax infection was much lower in East Shan in 2017 and increased sharply from 2017 to 2018 while others states showed a small decrease in 2017-2018.

\section{Seasonality and annual trend of malaria in Chinese border counties}

Reported malaria cases in the 18 border counties in China displayed well-defined seasonality in 20142018, with one peak from May to July and a slight peak from December to the following January (Fig. 6). This malaria transmission coincided with the environment and weather which was strongly correlated with the abundance of Anopheles. There are only two seasons in this border area, the rainy season from May to September and the dry season from October to the following April. The trend of total malaria cases in these 18 counties showed a steady decline except in 2015. There was only imported cases, with no indigenous malaria cases reported since 2017.

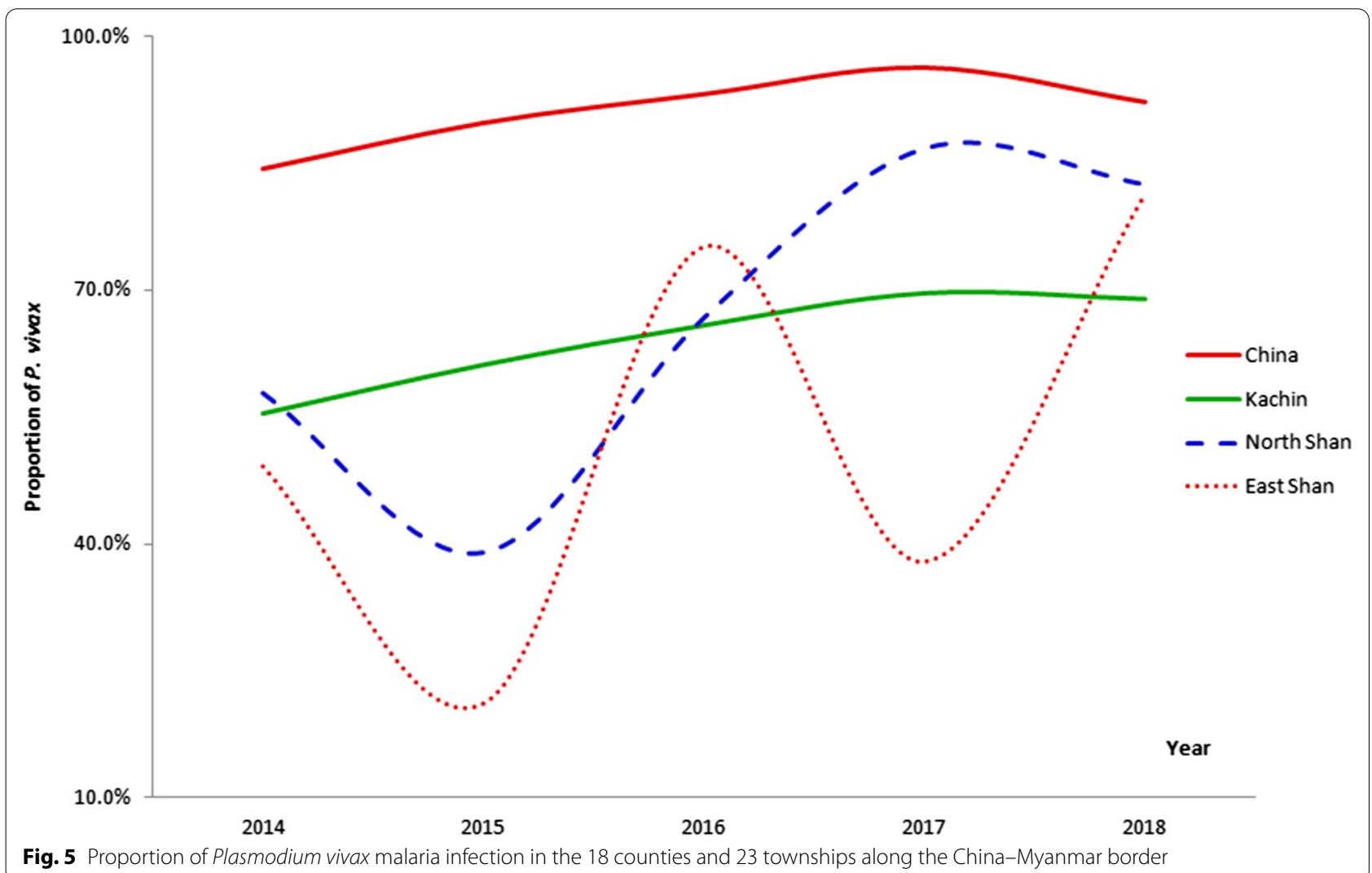



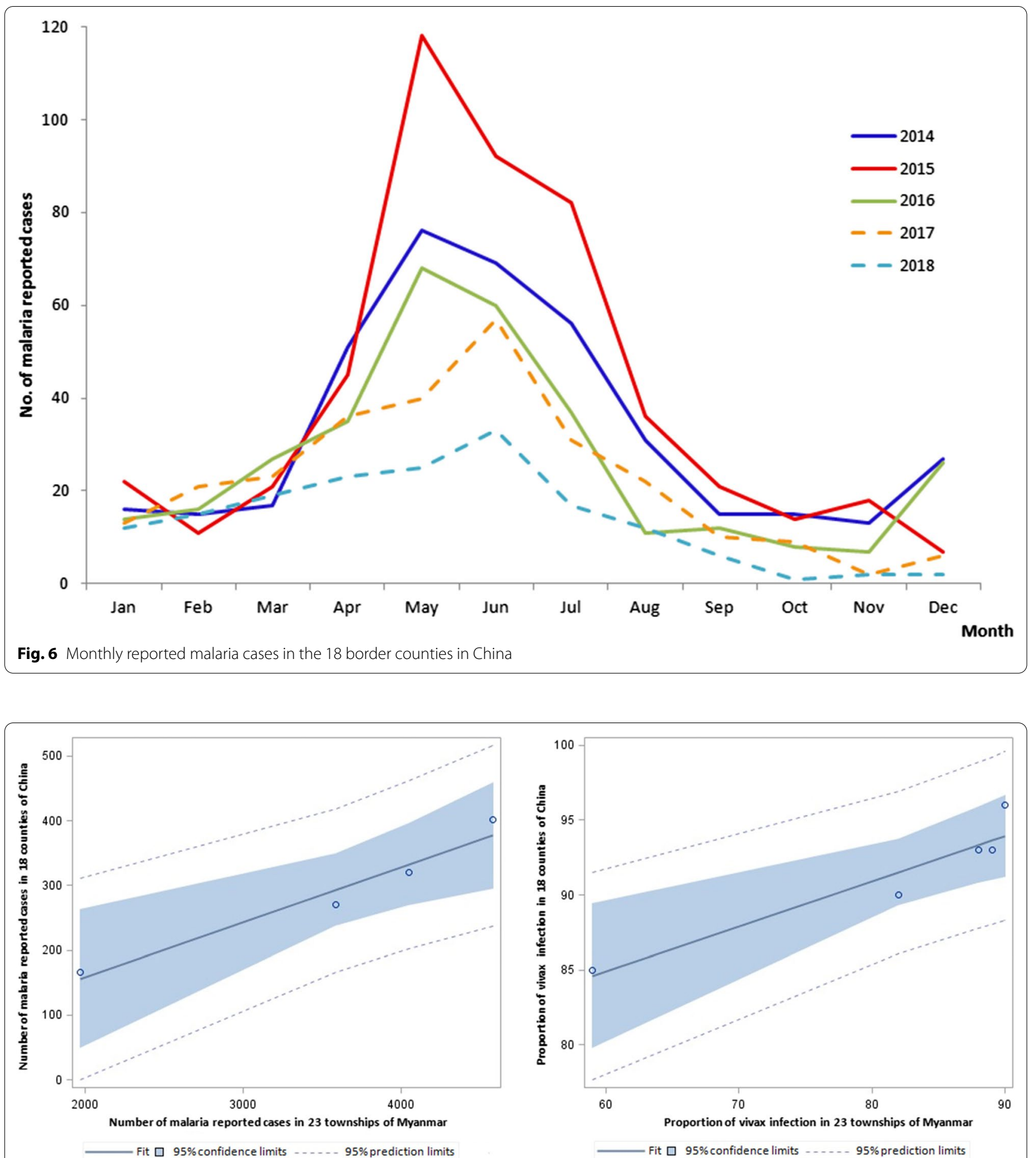

Fig. 7 The relationship of the number of reported malaria cases and proportion of vivax malaria infection between both sides of the border

The relationship of malaria endemicity between two sides of the border

The reported malaria cases and API on both sides decreased dramatically from 2014 to 2018 (Fig. 4). The proportion of vivax infection showed a significant correlation between both two sides of the border $\left(R^{2}=0.895\right.$, 95\% CI: 51.0471-82.4077). Similar results were obtained for the proportion of $P$. falciparum and mixed infections 
$\left(\mathrm{R}^{2}=0.9559 ; 95 \% \mathrm{CI}:-1.6672\right.$ to 5.2537$)$ (Fig. 7$)$. The number of reported malaria cases was correlated between the two side, with $\mathrm{R}^{2}$ of 0.9522 (95\% CI: -223.9488 to 201.2637) after the data for 2015 was removed $(P=0.0040)$. The API data had to be exponentially converted with a base of 2.5 to attain a normal distribution and homogeneity of variance. Interestingly, there was no significantly relationship of the APIs between the two sides of the border $(P>0.05)$.

\section{Discussion}

Malaria control has achieved great progress in China in the past decades, which were caused of effective control of the malaria epidemic and ensuring the health of the population along with the promotion of social and economic development [23]. More intensive work on surveillance and response in malaria endemic areas was seen after the NMEP was launched in 2010 [9, 24, 25]. With a strengthening surveillance and response system, the implementation of surveillance and response was standardized as a "1-3-7" surveillance approach, which means case reporting within 1 day, case investigation within 3 days and focus investigation and action within 7 days [26]. In our study, the total number of reported malaria cases in China fell 94.1\% from 2005 to 2018 (Fig. 2).The majority of the counties with indigenous malaria cases reported were located along the China-Myanmar border [27]. There have been no malaria indigenous malaria cases reported in China since 2017 [11] and China is approaching malaria elimination nationwide in 2020.

Myanmar is reported to account for the vast majority of malaria cases and deaths in the GMS [13]. The proportion of confirmed cases in Myanmar was much lower prior to 2012 (Fig. 3b), which may have been caused by limited access to early malaria diagnosis and appropriate treatment in the community. According to the National Plan for Malaria Elimination in Myanmar 2016-2020, the key interventions including early and effective malaria case management, universal coverage of high-risk populations with appropriate malaria prevention measures and case-based surveillance have been implemented for elimination and prevention of re-establishment in Myanmar. The significant progress has been achieved in reducing malaria morbidity and mortality, with the reduction of malaria cases by $72 \%$ from 2012 to 2018 , with a similar trend found in another study [28]. These achievements reflected a substantial improvement in case diagnosis and treatment and vector control, particularly at the periphery and among populations at risk of malaria, and increasing financial support from the Global Fund and other donors as well $[29,30]$. In response to the threaten by the emergence and spread of $P$. falciparum resistant to artemisinin, the world's first line antimalarial [31] in
Cambodia, Thailand, Vietnam, Laos and Myanmar [4, $32,33]$, WHO set its sights on malaria elimination in the GMS in order to contain this threat [6]. The National Plan for Malaria Elimination in Myanmar 2016-2030 has been developed with the goal of decreasing the API to $<1$ in all states/regions by 2020, interrupting transmission of falciparum malaria in all states/regions by 2025 and eliminating malaria nationwide by $2030[34,35]$.

Although great gains have been made in reducing the overall cases of malaria, achieving an impact from elimination and control efforts proves more difficult in areas near international borders [36, 37]. The specific environmental (including physical, social and geopolitical), anthropological, administrative and geographic characteristics of border areas have a unique impact on the epidemiology of malaria. Cross-border malaria is difficult to manage because of political, economic and geographic constraints [38]. Border malaria is a major obstacle to achieving malaria elimination in the GMS [39]. China and Myanmar share a border of around $2000 \mathrm{~km}$, which includes 18 counties in Yunnan Province of China and 13 townships from Kachin State, eight from Northern Shan State and two from Eastern Shan State in Myanmar [40]. The border counties on Yunnan side had the highest number of reported malaria cases in China [27] and the border townships in Myanmar had a relatively high transmission of malaria as well [41], resulting from lower access to health services, difficulties in deploying the prevention program to hard-to-reach communities, often in difficult terrain, and constant movement of people across porous national boundaries. The border counties in Yunnan Province are the key focus for malaria elimination in China and the 23 townships in Myanmar are one of the most difficult regions to be reached and covered by the NPME. This study showed that both reported malaria cases and API declined in the border counties or townships on both sides, but a few townships in Kachin State still had higher API, such as Injangyang, Momauk and Sumprabum. These townships should be the key focus for malaria elimination along this border.

When compared with P. falciparum, $P$. vivax is geographically the most widespread cause of human malaria with over 2.5 billion people living at risk of infection [42, 43]. Vivax malaria has a high prevalence in Southeast Asia, and in Central and South America. As reported by WHO, $53 \%$ of the P. vivax infection was in the WHO South-East Asia Region [1]. This study found that $P$. vivax was the predominant malaria parasite along the China-Myanmar border and the proportion of $P$. vivax infection increased from $61.6 \%$ in 2014 to $81.2 \%$ in 2018 with a very small decrease from 2017 to 2018 . This may be caused by the increasing imported cases with $P$. falciparum from Africa in Yunnan Province of China and 
multidrug resistance emerging of $P$. falciparum in GMS including Myanmar borders. Interestingly, the trend of proportion of $P$. vivax infection in East Shan showed the shape of "W". One reason may be some $P$. vivax cases were detected and recognized in remote area, which could be inferred from the small number of reported malaria cases in East Shan, i.e. Mengla only reported less than 10 malaria cases in 2015-2018. In addition, $P$. vivax was more common on Chinese side than on the Myanmar side. The epidemiology of vivax malaria in this region is highly complex and $P$. vivax has become a major challenge for malaria elimination in the GMS [13, 44].

The number of reported malaria cases and the proportion of vivax infection in the 18 Chinese counties was strongly correlated with those in the 23 townships of Myanmar $(P<0.05)$. Interestingly, we did not find a correlation of API between the two sides. API is defined as the number of confirmed new cases expressed per 1000 individuals under surveillance in a specific year, and it usually refers to areas of high and moderate malaria transmission risk $[45,46]$. The study data was obtained from the China-Myanmar border, which showed low to moderate transmission of malaria with a large mobile population and local population. This may lead to the bias when API is used as an indicator for regression analysis.

In addition, the similar climate and environment along the border area played one major role in malaria transmission, which were mostly through its effects on both the mosquito vector and the development of the malaria parasite inside the mosquito vector [47]. The diversity of malaria vectors in Yunnan Province was the highest in China. A total of 53 Anopheles species have been found, accounting for $88.3 \%$ of all Anopheles species reported in China. At least five Anopheles species or complexes were recorded as the predominant malaria vector in Yunnan Province, i.e. An. minimus, An. sinensis, An. kunming, An. anthropophagus, and An. dirus [38, 48]. An. minimus is the primary malaria vector along the China-Myanmar border.

The density of population and economic development in 18 Chinese border counties were higher than the border townships in Myanmar, which may have an indirect effect on the reduction of malaria [40]. Mobile population is also one of the risk factors for malaria control and elimination. A high proportion of mobile population was associated with greater malaria vulnerability in the China-Myanmar border region and the population-specific strategies and measures would be useful to decrease the risk of malaria re-establishment in China [38, 49]. Since 2014, a cross-border malaria prevention and control cooperation mechanism has been established between China and Myanmar to accelerate the control and elimination of malaria in this border region, and the strategic plan was drafted with "one zone one strategy" to promote the joint actions [7]. Efforts are underway to strengthen surveillance and to enhance reporting from the private sector and nongovernmental organizations (where relevant), with case-based surveillance and a response accelerating towards elimination. Based on the latest malaria epidemiology on the border, it is necessary to further promote the updating and implementation of this cooperation strategy and its action plan, highlighting the areas with high API in Myanmar side and high risk of malaria re-establishment in China side for achieving and maintaining the elimination in both the countries. Another point should be considered is that COVID-19 pandemic is affecting the global malaria control and elimination. WHO have published documents to provide guidance to ensure the maintenance essential malaria services at different level while working to control COVID-19 [50, 51].

One limitation of this study is that malaria data was analyzed in a large scale, which was based on the county or township level. However, malaria cases were more scattered in the villages or communities in the pre-elimination or elimination stage. The further spatial-temporal analysis of malaria in small scale at village or community level will be more accurate.

\section{Conclusions}

There has been a dramatic declined in malaria incidence along the China-Myanmar border and malaria elimination is approaching along the China-Myanmar border. However, in order to achieve the malaria elimination in this region and prevent the re-establishment of malaria in China after elimination, continued political, financial and scientific commitment and joint actions are still required.

\section{Abbreviations \\ ACTs: Artemisinin-based combination therapies; API: Annual parasite index; GMS: Greater Mekong Subregion; ITNs: Insecticide-treated nets; NMCP: National Malaria Control Programme; NMEP: National Malaria Elimination Programme; PCR: Polymerase chain reaction; RDT: Rapid diagnostic test; WHO: World Health Organization.}

\section{Acknowledgements}

We thank the staffs for their efforts and assistances in data collection in China and Myanmar.

\section{Authors' contributions}

FH, ZGX, XNZ conceived and designed the study; SSZ, QFZ, QZ and AT contributed to malaria data collection; HNZ, SSZ and XNZ contributed to the review and editing of the manuscript; FH, LZ, JBX carried out the data analysis; FH drafted the manuscript. All authors read and approved the final manuscript.

\section{Funding}

This work was supported by the Natural Science Foundation of Shanghai (No. 18ZR1443400), the National Important Scientific \& Technological Project 2018ZX10101002-002), the Forge Ahead Together for Elimination Towards Malaria free China-Myanmar border and National Malaria Elimination Program of China. 


\section{Availability of data and materials}

The datasets used and/or analysed during the current study are available from the corresponding author on reasonable request.

\section{Ethics approval and consent to participate}

Not applicable.

\section{Consent for publication}

Not applicable.

\section{Competing interests}

Xiao-Nong Zhou is an Editor-in-Chief of the journal Infectious Diseases of Poverty. He was not involved in the peer-review or handling of the manuscript. The authors have no other competing interests to disclose.

\section{Author details}

${ }^{1}$ National Institute of Parasitic Diseases, Chinese Center for Disease Contro and Prevention, Chinese Center for Tropical Diseases Research, WHO Collaborating Center for Tropical Diseases, National Centre for International Research on Tropical Diseases, Ministry of Science and Technology, Key Laboratory of Parasite and Vector Biology, Ministry of Health, Shanghai 200025, China. ${ }^{2}$ Yunnan Institute of Parasitic Diseases, Puer 665000, China. ${ }^{3}$ Department of Public Health, Ministry of Health and Sports, Nay Pyi Taw 15011, Myanmar.

${ }^{4}$ Health Poverty Action East Asia Programme Office, Kunming 650000, China.

Received: 28 September 2020 Accepted: 6 November 2020

Published online: 19 November 2020

\section{References}

1. WHO. World malaria report 2019. Geneva: World Health Organization; 2019.

2. Menard D, Khim N, Beghain J, Adegnika AA, Shafiul-Alam M, Amodu O, et al. A worldwide map of Plasmodium falciparum K13-propeller polymorphisms. N Engl J Med. 2016;374:2453-64.

3. Takala-Harrison S, Jacob CG, Arze C, Cummings MP, Silva JC, Dondorp $\mathrm{AM}$, et al. Independent emergence of artemisinin resistance mutations among Plasmodium falciparum in Southeast Asia. J Infect Dis. 2015;211:670-9.

4. Ashley EA, Dhorda M, Fairhurst RM, Amaratunga C, Lim P, Suon S, et al. Spread of artemisinin resistance in Plasmodium falciparum malaria. N Engl J Med. 2014;371:411-23.

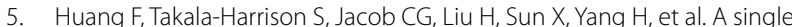
mutation in $\mathrm{K} 13$ predominates in Southern China and is associated with delayed clearance of Plasmodium falciparum following artemisinin treatment. J Infect Dis. 2015;212:1629-35.

6. WHO. Strategy for malaria elimination in the GMS (2015-2030). Geneva: World Health Organization; 2015a.

7. Inkochasan M, Gopinath D, Vicario E, Lee A, Duigan P. Access to health care for migrants in the Greater Mekong Subregion: policies and legal frameworks and their impact on malaria control in the context of malaria elimination. WHO South East Asia J Public Health. 2019;8(1):26-34.

8. Yin JH, Zhou SS, Xia ZG, Wang RB, Qian YJ, Yang WZ, et al. Historical patterns of malaria transmission in China. Adv Parasitol. 2014;86:1-19.

9. Feng X, Xia ZG, Feng J, Zhang L, Yan H, Tang L, et al. The contributions and achievements on malaria control and forthcoming elimination in China over the past 70 years by NIPD-CTDR. Adv Parasitol. 2020;110:63-105.

10. Hu T, Liu YB, Zhang SS, Xia ZG, Zhou SS, Yan J, et al. Shrinking the malaria map in China: measuring the progress of the National Malaria Elimination Programme. Infect Dis Poverty. 2016;5(1):52.

11. Feng J, Zhang L, Huang F, Yin JH, Tu H, Xia ZG, et al. Ready for malaria elimination: zero indigenous case reported in the People's Republic of China. Malar J. 2018;17(1):315.

12. Delacollette C, D'Souza C, Christophel E, Thimasarn K, Abdur R, Bell D, et al. Malaria trends and challenges in the Greater Mekong Subregion. Southeast Asian J Trop Med Public Health. 2009;40(4):674-91.

13. Cui L, Yan G, Sattabongkot J, Cao Y, Chen B, Chen X, et al. Malaria in the Greater Mekong Subregion: heterogeneity and complexity. Acta Trop. 2012:121:227-39.
14. Hein ZNM, Maung TM, Aung PP, Mon NO, Han WW, Oo T, et al. Do we need to go further to train healthcare providers in the targeted regions for malaria elimination in Myanmar? A mixed-methods study. Trop Med Health. 2020;48:11.

15. Hewitt SE. Let's "cut to the chase" on malaria elimination in the Greater Mekong Subregion. Trans R Soc Trop Med Hyg. 2019;113:161-2.

16. Hewitt S, Delacollette C, Poirot E. Malaria control in the Greater Mekong Subregion: an overview of the current response and its limitations. Southeast Asian J Trop Med Public Health. 2013;44(Suppl 1):249-305 (discussion 306-7)

17. Hlaing T, Wai KT, Oo T, Sint N, Min T, Myar S, et al. Mobility dynamics of migrant workers and their socio-behavioral parameters related to malaria in Tier II, Artemisinin Resistance Containment Zone, Myanmar. BMC Public Health. 2015:15:886.

18. Ghinai I, Cook J, Hla TT, Htet HM, Hall T, Lubis IN, et al. Malaria epidemiology in central Myanmar: identification of a multi-species asymptomatic reservoir of infection. Malar J. 2017;16:16.

19. Win AYN, Maung TM, Wai KT, Oo T, Thi A, Tipmontree R, et al. Understanding malaria treatment-seeking preferences within the public sector amongst mobile/migrant workers in a malaria elimination scenario: a mixed-methods study. Malar J. 2017;16:462.

20. Programme NMC. Malaria surveillance in elimination settings: an operational manual 2018 Version 1.0. Nay Pyi Taw: National Malaria Control Programme; 2018.

21. Zhang J, Dong JQ, Li JY, Zhang Y, Tian YH, Sun XY, et al. Effectiveness and impact of the cross-border healthcare model as implemented by nongovernmental organizations: case study of the malaria control programs by health poverty action on the China-Myanmar border. Infect Dis Poverty. 2016;5(1):80.

22. Yin JH, Yan H, Huang F, Li M, Xiao HH, Zhou SS, Xia ZG. Establishing a China malaria diagnosis reference laboratory network for malaria elimination. Malar J. 2015;14:40

23. Shou-Pai M. Parasitological research in institutes in China. New York: Springer; 1983

24. Xia S, Zheng JX, Wang XY, Xue JB, Hu JH, Zhang XQ, et al. Epidemiological big data and analytical tools applied in the control programmes on parasitic diseases in China: NIPD's sustained contributions in 70 years. Adv Parasitol. 2020;110:319-47.

25. Yang CY, Qian D, Lu DL, Liu Y, Zhou RM, Li SH, et al. Epidemic status of malaria and progress of malaria elimination in Henan Province, 2018. Zhongguo Xue Xi Chong Bing Fang Zhi Za Zhi. 2020;32(3):298-300 (In Chinese).

26. Cao J, Sturrock HJ, Cotter C, Zhou S, Zhou H, Liu Y, et al. Communicating and monitoring surveillance and response activities for malaria elimination: China's"1-3-7" strategy. PLoS Med. 2014;11:e1001642.

27. Feng J, Liu J, Feng X, Zhang L, Xiao H, Xia Z. Towards malaria elimination: monitoring and evaluation of the "1-3-7" approach at the China-Myanmar border. Am J Trop Med Hyg. 2016;95:806-10.

28. Mu TT, Sein AA, Kyi TT, Min M, Aung NM, Anstey NM, et al. Malaria incidence in Myanmar 2005-2014: steady but fragile progress towards elimination. Malar J. 2016:15:503.

29. McLean ARD, Wai HP, Thu AM, Khant ZS, Indrasuta C, Ashley EA, et al. Malaria elimination in remote communities requires integration of malaria control activities into general health care: an observational study and interrupted time series analysis in Myanmar. BMC Med. 2018;16:183.

30. Nyunt MH, Aye KM, Kyaw KT, Han SS, Aye TT, Wai KT, et al. Challenges encountered by local health volunteers in early diagnosis and prompt treatment of malaria in Myanmar artemisinin resistance containment zones. Malar J. 2016;15:308.

31. WHO. Guidelines for the treatment of malaria-3rd edition. Geneva: World Health Organization; 2015b.

32. Dondorp AM, Nosten F, Yi P, Das D, Phyo AP, Tarning J, et al. Artemisinin resistance in Plasmodium falciparum malaria. N Engl J Med. 2009:361:455-67.

33. Noedl H, Se Y, Sriwichai S, Schaecher K, Teja-Isavadharm P, Smith B, et al. Artemisinin resistance in Cambodia: a clinical trial designed to address an emerging problem in Southeast Asia. Clin Infect Dis. 2010;51:e82-9.

34. Kaehler N, Adhikari B, Cheah PY, von Seidlein L, Day NPJ, Paris DH, et al. Prospects and strategies for malaria elimination in the Greater Mekong Sub-region: a qualitative study. Malar J. 2019;18:203. 
35. National MCP. National plan for malaria elimination in Myanmar 20162030. Nay Pyi Taw: National Malaria Control Program Myanmar; 2017.

36. Al Zahrani MH, Omar Al, Abdoon AMO, Ibrahim AA, Alhogail A, Elmubarak $M$, et al. Cross-border movement, economic development and malaria elimination in the Kingdom of Saudi Arabia. BMC Med. 2018;16:98.

37. Wangdi K, Gatton ML, Kelly GC, Clements AC. Cross-border malaria: a major obstacle for malaria elimination. Adv Parasitol. 2015;89:79-107.

38. Xu J, Liu H. Border malaria in Yunnan, China. Southeast Asian J Trop Med Public Health. 1997:28(3):456-9.

39. Carrara VI, Lwin KM, Phyo AP, Ashley E, Wiladphaingern J, Sriprawat K, et al. Malaria burden and artemisinin resistance in the mobile and migrant population on the Thai-Myanmar border, 1999-2011: an observational study. PLoS Med. 2013;10:e1001398.

40. Zhao X, Thanapongtharm W, Lawawirojwong S, Wei C, Tang Y, Zhou Y, et al. Spatiotemporal trends of malaria in relation to economic development and cross-border movement along the China-Myanmar border in Yunnan Province. Korean J Parasitol. 2020;58:267-78.

41. Xu JW, Liu H. The relationship of malaria between Chinese side and Myanmar's five special regions along China-Myanmar border: a linear regression analysis. Malar J. 2016;15:368.

42. Howes RE, Battle KE, Mendis KN, Smith DL, Cibulskis RE, Baird JK, et al. Global epidemiology of Plasmodium vivax. Am J Trop Med Hyg. 2016;95:15-34

43. Mendis K, Sina BJ, Marchesini P, Carter R. The neglected burden of Plasmodium vivax malaria. Am J Trop Med Hyg. 2001;64:97-106.
44. Chen SB, Wang Y, Kassegne K, Xu B, Shen HM, Chen JH. Whole-genome sequencing of a Plasmodium vivax clinical isolate exhibits geographical characteristics and high genetic variation in China-Myanmar border area. BMC Genomics. 2017;18:131.

45. Kheang ST, Sovannaroth S, Barat LM, Dysoley L, Kapella BK, Po L, et al. Malaria elimination using the 1-3-7 approach: lessons from Sampov Loun, Cambodia. BMC Public Health. 2020;20:544.

46. Lima ID, Lapouble OM, Duarte EC. Time trends and changes in the distribution of malaria cases in the Brazilian Amazon Region, 2004-2013. Mem Inst Oswaldo Cruz. 2017;112:8-18.

47. Thomson M, Indeje M, Connor S, Dilley M, Ward N. Malaria early warning in Kenya and seasonal climate forecasts. Lancet. 2003;362(9383):580.

48. Dong XS. Fauna Sinaca of Yunnan province, P. R. China. Kunming: Yunnan Science and Technology Press; 2010. (In Chinese)

49. Chen TM, Zhang SS, Feng J, Xia ZG, Luo CH, Zeng XC, et al. Mobile population dynamics and malaria vulnerability: a modelling study in the China-Myanmar border region of Yunnan Province, China. Infect Dis Poverty. 2018;7(1):36

50. WHO. Maintaining essential health services: operational guidance for the COVID-19 context interim guidance. Geneva: World Health Organization; 2020a.

51. WHO. The potential impact of health service disruptions on the burden of malaria: a modelling analysis for countries in sub-Saharan Africa. Geneva: World Health Organization; 2020b.
Ready to submit your research? Choose BMC and benefit from:

- fast, convenient online submission

- thorough peer review by experienced researchers in your field

- rapid publication on acceptance

- support for research data, including large and complex data types

- gold Open Access which fosters wider collaboration and increased citations

- maximum visibility for your research: over 100M website views per year

At BMC, research is always in progress.

Learn more biomedcentral.com/submissions 